\title{
Widespread cytotypic variation, cytogeography and dynamic analysis of Lysimachia mauritiana (Primulaceae) on Takarajima Island in the Ryukyu Archipelago of Japan
}

\author{
Yoshiko Kono $^{1}$, Yoshikazu Hoshi ${ }^{2,6}$, Hiroaki Setoguchi ${ }^{3}$, \\ Masatsugu Yokota ${ }^{4}$ and Kazuo Oginuma ${ }^{5}$ \\ ${ }^{1}$ Graduate School of Human Health Sciences, University of Kochi, 5-15 Eikokuji-cho, \\ Kochi 780-8515, Japan; ${ }^{2}$ Department of Plant Science, School of Agriculture, \\ Tokai University, Kawayo, Minamiaso-mura, Aso-gun, Kumamoto \\ 869-1404, Japan; ${ }^{3}$ Graduate School of Human and Environmental \\ Studies, Kyoto University, Yoshidanihonmatsu-cho, Sakyo-ku, \\ Kyoto 606-8501, Japan; ${ }^{4}$ Laboratory of Ecology and Systematics, \\ Faculty of Science, University of the Ryukyus, 1 Senbaru, \\ Nishihara-cho, Nakagami-gun, Okinawa 903-0213, Japan; \\ ${ }_{5}^{5}$ Department of Biology, Faculty of Human Life and \\ Environmental Science, University of Kochi, 5-15 \\ Eikokuji-cho, Kochi 780-8515, Japan \\ ${ }^{6}$ Author for correspondence (yhoshi@agri.u-tokai.ac.jp) \\ Received 24 June 2013; accepted August 7, 2013
}

\begin{abstract}
Lysimachia mauritiana displayed a comprehensive karyotypic polymorphism (18 cytotypes) in the Ryukyu Archipelago of Japan. To explore chromosome variation on Takarajima Island, karyomorphological analysis was made in 238 individuals from six localities throughout the island. Total five different chromosome numbers $(2 n=16,17,18,19,20)$ and 11 cytotypes were recognized in the area. In the localities of the island, multiple cytotypes coexisted and diversified every year among and within population, although populational coexistence of plural cytotypes was maintained. Especially, three cytotypes of 16 $(6 \mathbf{m}), 17(5 \mathbf{m})$ and $18(4 \mathbf{m})$ co-occurred in every locality, indicating that they were involved in a formation of cytotypes in Takarajima Island.
\end{abstract}

KEYWORDS: Cytogeography, Cytotypic variation, Lysimachia mauritiana, Takarajima Island, Ryukyu Archipelago

The Ryukyu Archipelago of Japan「(the Ryukyus) $\rfloor$, located between Kyushu District of Japan and Taiwan, constitutes an arc of continental islands lying on the Pacific rim of Eurasia. In order from north to south, it is divided into two major groups: the Satsunan belonging to Kagoshima Prefecture and the Ryukyu, Okinawa Prefecture. Each group is subdivided to the Osumi, Tokara and Amami groups, and the Ryukyu sensu stricto, Daito and Sakishima groups, respectively (Fig. 1a). Because these islands stretched across temperate and subtropical zones, and were repeatedly connected and separated with surrounding islands due to changeable sea level originated from climate changes during the Cenozoic Era, the area is suitable for biogeographical studies (cf. Ota 2000). Although many phylogeographical studies have been documented in plants from the area (Kyoda and Setoguchi 2010; Nakamura et al. 2010; Nomura et al. 2010; Mitsui and Setoguchi 2012), cytogeographical investigations are still limited throughout the Ryukyus (Denda and Yokota 2004).

A biennial seaside plant Lysimachia mauritiana Lam. (Primulaceae) has a wide distribution in East Asia, especially Japan, Korea and Taiwan, the Philippines and islands in the Pacific and Indian Oceans (Iwatsuki et al. 1993; Shimabuku 1997). The species frequently grows on rocky coasts, sometimes on sandy beaches. In the past decade, we explored karyomorphologies of the species from the Ryukyus and Taiwan, and revealed a remarkable intraspecific karyotypic polymorphism: five different chromosome numbers and 18 cytotypes in the Ryukyus (Oginuma et al. 2004a; Kono et al. 2008, 2010) and four different chromosome numbers and eight cytotypes in Taiwan (Oginuma et al. 2004b; Kono et al. 2012). To our knowledge, intraspecific chromosomal variation especially in the Ryukyus has been documented in several plants, i.e., Asteraceae (Ixeris nakazonei: Denda and Yokota 2004), Cyperaceae (Carex sociata: Ohkawa et al. 2000), Hydrangeaceae (Hydrangea liukiuensis and $H$. yayeyamensis: Akiyama 1989) and Urticaceae (Elatostema suzukii: Yamashiro et al. 2000). With one exception (Ohkawa et al. 2000), all the plants documented, however, were polyploidal variations in chromosome numbers. Therefore, L. mauritiana with the intraspecific karyotypic polymorphism was a significant rare plant in the Ryukyus.

Moreover, L. mauritiana showed a coexistence of multiple cytotypes within a population mainly in the central Ryukyus, islands from Takarajima Is. to Okinawajima Is. (see Table 1 in Kono et al. 2008, 2010), and also four localities of Taiwan (Kono et al. 2012). Specifically in Taiwan, cytotype distributions were clearly structured geographically most localities had single cytotype; four major cytotypes dominated the north, east and south of 


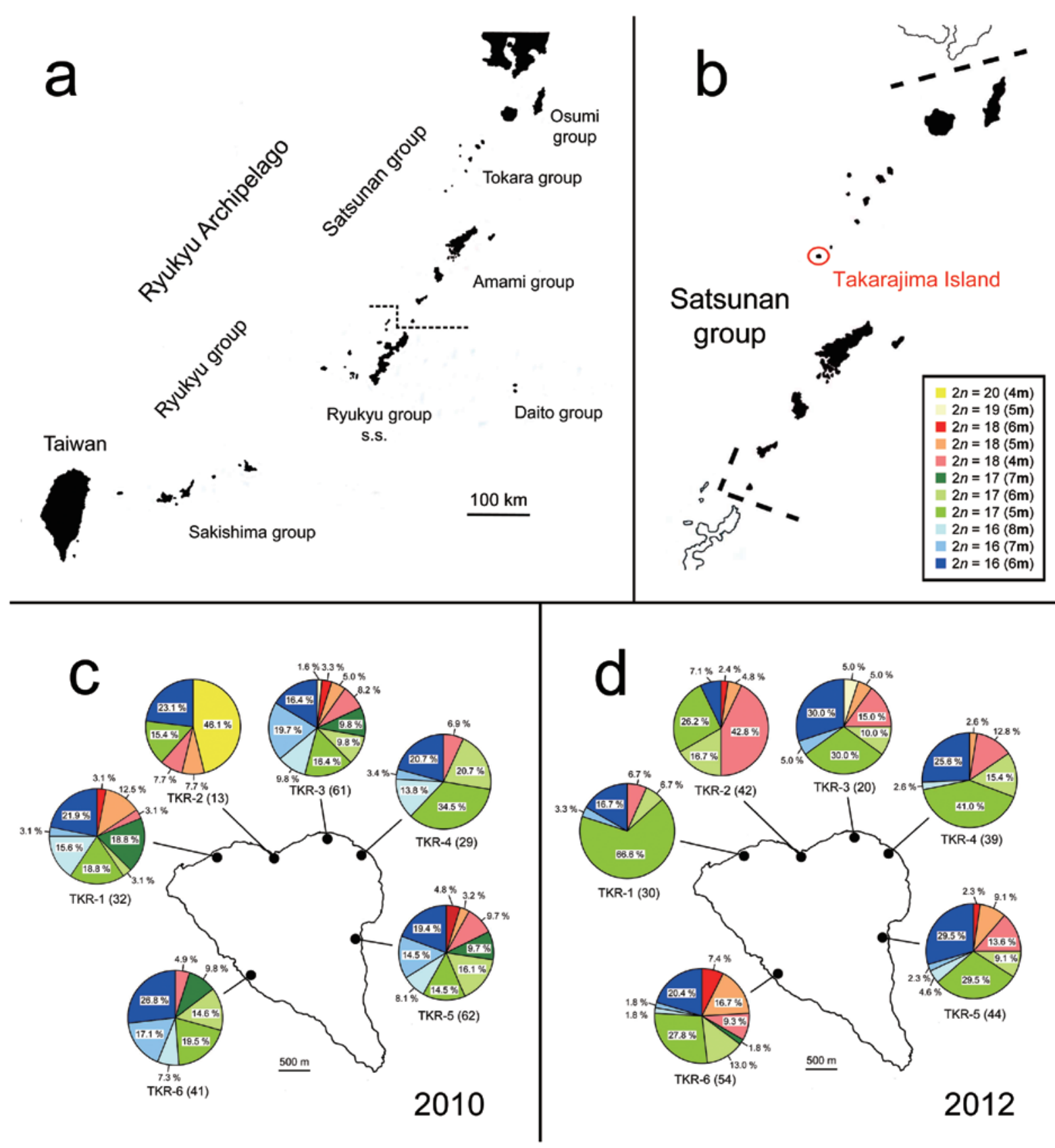

Fig. 1. Collection localities for karyotypic and cytogeographic analyses of Lysimachia mauritiana on Takarajima Island, Japan. (a) Location of the Ryukyu Archipelago of Japan and Taiwan. (b) Map showing islands belonging to the Satsunan group. The island with a red circle indicates Takarajima Island investigated here. (c) and (d) Appearance frequencies and cytogeography of cytotypes in six localities on Takarajima Island. (c) was conducted in 2010; (d) in 2012 .

Taiwan and the Penghu Is. However, none of detailed reports of intra-populational karyotypic analysis and cytogeographical structure were conducted in the Ryukyus. Thus, by focusing on the intra-populational karyotypic polymorphism and its cytogeography of the species from the central Ryukyus, a series of studies are conducted hereafter. The present study targeted the plants on the northernmost island of the central Ryukyus, Takarajima Is., with ca. $14 \mathrm{~km}$ around, $c a .300 \mathrm{~m}$ high and ca. $7 \mathrm{~km}^{2}$ in area (Fig. 1b). The aims were to: (1) investigate different chromosome numbers and cytotypes; (2) determine intra-populational multiple cytotypes; (3) reveal dynamics of intra-populational cytotypes after two years.

\section{Materials and Methods}

In total 238 individuals of Lysimachia mauritiana from six populations throughout Takarajima Is. were karyotypically and cytogeographically analyzed for the first time in 2010 (Table 1; Fig. 1c). 13 to 62 plants per locality were collected and its average was 39.7 plants. Habitats of all localities were similar, sandy and/or gravel coasts of raised coral reefs. Each sample with rosette leaves, $5-8 \mathrm{~cm}$ in diameter, was randomly collected at $30-50 \mathrm{~cm}$ intervals 
Table 1. Collection localities and karyotypes of 238 plants in 2010 and 229 plants in 2012 of Lysimachia mauritiana collected from six populations on Takarajima Island

\begin{tabular}{|c|c|c|c|c|c|}
\hline \multirow[t]{2}{*}{ Population } & \multirow[t]{2}{*}{ Latitude (N) / Longitude (E) } & \multicolumn{2}{|r|}{ Karyotype $\dagger$} & \multirow{2}{*}{$\begin{array}{c}\text { No. of plants } \\
\text { in } 2010 \\
\end{array}$} & \multirow{2}{*}{$\begin{array}{c}\text { No. of plants } \\
\text { in } 2012 \\
\end{array}$} \\
\hline & & $2 n$ & Formula & & \\
\hline TKR-1 & $29^{\circ} 09^{\prime} 21^{\prime \prime} / 129^{\circ} 11^{\prime} 43^{\prime \prime}$ & 18 & $\begin{array}{l}6 \mathbf{m}+2 s m+10 t \\
5 \mathbf{m}+1 \mathrm{~m}+2 \mathrm{sm}+10 \mathrm{t} \\
4 \mathbf{m}+2 \mathrm{~m}+2 \mathrm{sm}+10 \mathrm{t} \\
7 \mathbf{m}+2 \mathrm{sm}+8 \mathrm{t} \\
6 \mathbf{m}+2 \mathrm{sm}+1 \mathrm{st}+8 \mathrm{t} \\
5 \mathbf{m}+2 \mathrm{~m}+2 \mathrm{sm}+8 \mathrm{t} \\
8 \mathbf{m}+2 \mathrm{sm}+6 \mathrm{t} \\
7 \mathbf{m}+3 \mathrm{sm}+6 \mathrm{t} \\
6 \mathbf{m}+4 \mathrm{sm}+6 \mathrm{t}\end{array}$ & $\begin{array}{c}1 \\
4 \\
1 \\
6 \\
1 \\
6 \\
5 \\
1 \\
7 \\
(\mathrm{~N}=32)^{*}\end{array}$ & $\begin{array}{c}0 \\
0 \\
2 \\
0 \\
2 \\
20 \\
0 \\
1 \\
5 \\
(\mathrm{~N}=30)\end{array}$ \\
\hline TKR-2 & $29^{\circ} 09^{\prime} 27^{\prime \prime} / 129^{\circ} 12^{\prime} 12^{\prime \prime}$ & $\begin{array}{l}17 \\
16\end{array}$ & $\begin{array}{l}4 \mathbf{m}+2 s m+4 s t+10 t \\
6 \mathbf{m}+2 s m+10 t \\
5 \mathbf{m}+2 s m+1 s t+10 t \\
4 \mathbf{m}+4 s m+10 t \\
6 \mathbf{m}+3 s m+8 t \\
5 \mathbf{m}+2 s m+2 s t+8 t \\
6 \mathbf{m}+2 s m+2 s t+6 t\end{array}$ & $\begin{array}{c}6 \\
0 \\
1 \\
1 \\
0 \\
2 \\
3 \\
(\mathrm{~N}=13)\end{array}$ & $\begin{array}{c}0 \\
1 \\
2 \\
18 \\
7 \\
11 \\
3 \\
(\mathrm{~N}=42)\end{array}$ \\
\hline TKR-3 & $29^{\circ} 09^{\prime} 27^{\prime \prime} / 129^{\circ} 12^{\prime} 52^{\prime \prime}$ & $\begin{array}{l}19 \\
18\end{array}$ & $\begin{array}{l}5 \mathbf{m}+2 s m+2 s t+10 t \\
6 \mathbf{m}+2 s m+10 t \\
5 \mathbf{m}+1 m+2 s m+10 t \\
4 \mathbf{m}+2 s m+2 s t+10 t \\
7 \mathbf{m}+2 s m+8 t \\
6 \mathbf{m}+2 s m+1 s t+8 t \\
5 \mathbf{m}+2 s m+2 s t+8 t \\
8 \mathbf{m}+2 s m+6 t \\
7 \mathbf{m}+3 s m+6 t \\
6 \mathbf{m}+4 s m+6 t\end{array}$ & $\begin{array}{c}1 \\
2 \\
3 \\
5 \\
6 \\
6 \\
10 \\
6 \\
12 \\
10 \\
(\mathrm{~N}=61)\end{array}$ & $\begin{array}{c}1 \\
0 \\
1 \\
3 \\
0 \\
2 \\
6 \\
0 \\
1 \\
6 \\
(\mathrm{~N}=20)\end{array}$ \\
\hline TKR-4 & $29^{\circ} 09^{\prime} 20^{\prime \prime} / 129^{\circ} 13^{\prime} 09^{\prime \prime}$ & 17 & $\begin{array}{l}5 \mathbf{m}+3 s m+10 t \\
4 \mathbf{m}+2 s m+2 s t+10 t \\
6 \mathbf{m}+2 s m+1 s t+8 t \\
5 \mathbf{m}+2 s m+2 s t+8 t \\
8 m+2 s m+6 t \\
7 \mathbf{m}+1 m+2 s m+6 t \\
6 m+4 s m+6 t\end{array}$ & $\begin{array}{c}0 \\
2 \\
6 \\
10 \\
4 \\
1 \\
6 \\
(\mathrm{~N}=29)\end{array}$ & $\begin{array}{c}1 \\
5 \\
6 \\
16 \\
1 \\
0 \\
10 \\
(\mathrm{~N}=39)\end{array}$ \\
\hline TKR-5 & $29^{\circ} 08^{\prime} 43^{\prime \prime} / 129^{\circ} 13^{\prime} 03^{\prime \prime}$ & 17 & $\begin{array}{l}6 \mathbf{m}+2 s m+10 t \\
5 \mathbf{m}+2 s m+1 s t+10 t \\
4 \mathbf{m}+2 s m+2 s t+10 t \\
7 \mathbf{m}+2 s m+8 t \\
6 \mathbf{m}+2 s m+1 s t+8 t \\
5 \mathbf{m}+2 s m+2 s t+8 t \\
8 \mathbf{m}+2 s m+6 t \\
7 \mathbf{m}+3 s m+6 t \\
6 \mathbf{m}+4 s m+6 t\end{array}$ & $\begin{array}{c}3 \\
2 \\
6 \\
6 \\
10 \\
9 \\
5 \\
9 \\
12 \\
(\mathrm{~N}=62)\end{array}$ & $\begin{array}{c}1 \\
4 \\
6 \\
0 \\
4 \\
13 \\
2 \\
1 \\
13 \\
(\mathrm{~N}=44)\end{array}$ \\
\hline TKR-6 & $29^{\circ} 08^{\prime} 29^{\prime \prime} / 129^{\circ} 12^{\prime} 03^{\prime \prime}$ & 17 & $\begin{array}{l}6 \mathbf{m}+2 s m+10 t \\
5 \mathbf{m}+3 s m+10 t \\
4 \mathbf{m}+2 m+2 s m+10 t \\
7 \mathbf{m}+2 s m+8 t \\
6 \mathbf{m}+2 s m+1 s t+8 t \\
5 \mathbf{m}+2 s m+2 s t+8 t \\
8 \mathbf{m}+2 s m+6 t \\
7 \mathbf{m}+3 s m+6 t \\
6 \mathbf{m}+4 s m+6 t\end{array}$ & $\begin{array}{c}0 \\
0 \\
2 \\
4 \\
6 \\
8 \\
3 \\
7 \\
11 \\
(\mathrm{~N}=41)\end{array}$ & $\begin{array}{c}4 \\
9 \\
5 \\
1 \\
7 \\
15 \\
1 \\
1 \\
11 \\
(\mathrm{~N}=54)\end{array}$ \\
\hline
\end{tabular}

* $\mathrm{N}$, the total number of individuals for the karyologically analyses

$\uparrow$ Predominant karyotypes of respective localities are listed. $\mathbf{m}$, longer metacentric chromosome used as the marker chromosomes 
to avoid collecting seedlings from the same plant. After field works, samples were cultivated in the experimental greenhouse of University of Kochi. For karyotypic analyses, somatic chromosomes were examined using root tips; methods of pretreatment, fixation and staining were described in Kono et al. (2012). Classifications of chromosome morphology on the basis of the centromeric position followed Levan et al. (1964). Voucher specimens were deposited in the herbarium of University of the Ryukyus (RYU). Over the last decade, we have investigated the karyotypic polymorphism of L. mauritiana in the Ryukyus and Taiwan (Oginuma et al. 2004a, b; Kono et al. 2008, 2010, 2012). Through them including the present study, the marker chromosomes designed as bold ' $m$ ' (longer metacentric chromosomes) and 'cytotype(s)' were consistently applied for the simplification of the wideranged karyotypic polymorphism (see Kono et al. 2012 for more information).

Likewise, the additional sampling was conducted in 2012, and 229 individuals (38.2 plants in average) were collected from the same localities of the island for dynamic analyses of cytotypes in the respective localities (Table 1; Fig. 1d). The procedures of collecting plants, chromosome observations and karyotypic analyses were totally same as described above.

\section{Results and Discussion}

Karyotypic polymorphism and cytogeography Chromosome numbers and predominant karyotypic formulae of Lysimachia mauritiana in each locality were shown in Table 1. In 2010, five different chromosome numbers, $2 n=16,17,18,19,20$, and 11 cytotypes on the basis of the marker chromosomes, namely $2 n=16(6 \mathbf{m}),(7 \mathbf{m}),(8 \mathbf{m})$; 17 (5m), (6m), (7m); 18 (4m), (5m), (6m); 19 (5m); 20 $(4 \mathbf{m})$, were identified in a total of 238 individuals. Additionally, intra-populational variations in cytotypes of the species were observed in all localities and their appearance frequencies in respective localities were as follows (Table 1; Fig. 1c):

(1) TKR-1 Nine cytotypes co-occurred: $21.9 \%$ in 16 (6m); $18.8 \%$ in $17(5 \mathbf{m})$ and $17(7 \mathbf{m}) ; 15.6 \%$ in $16(8 \mathbf{m})$; $12.5 \%$ in $18(5 \mathbf{m}) ; 3.1 \%$ in $16(7 \mathbf{m}), 17(6 \mathbf{m}), 18(4 \mathbf{m})$ and $18(6 \mathbf{m})$.

(2) $\boldsymbol{T K R}-2$ Five cytotypes co-occurred: $46.1 \%$ in 20 (4m); $23.1 \%$ in $16(6 \mathbf{m}) ; 15.4 \%$ in $17(5 \mathbf{m}) ; 7.7 \%$ in 18 $(4 \mathbf{m})$ and $18(5 \mathbf{m})$.

(3) $\boldsymbol{T K R}$-3 Ten cytotypes co-occurred: $19.7 \%$ in 16 (7m); $16.4 \%$ in $16(6 \mathbf{m})$ and $17(5 \mathbf{m}) ; 9.8 \%$ in $16(8 \mathbf{m})$, $17(6 \mathbf{m})$ and $17(7 \mathbf{m}) ; 8.2 \%$ in $18(4 \mathbf{m}) ; 5.0 \%$ in $18(5 \mathbf{m})$; $3.3 \%$ in $18(6 \mathbf{m}) ; 1.6 \%$ in $19(5 \mathbf{m})$.

(4) $T K R-4$ Six cytotypes co-occurred: $34.5 \%$ in 17
$(5 \mathbf{m}) ; 20.7 \%$ in $16(6 \mathbf{m})$ and $17(6 \mathbf{m}) ; 13.8 \%$ in $16(8 \mathbf{m})$; $6.9 \%$ in $18(4 \mathrm{~m}) ; 3.4 \%$ in $16(7 \mathbf{m})$.

(5) TKR-5 Nine cytotypes co-occurred: $19.4 \%$ in 16 $(6 \mathbf{m}) ; 16.1 \%$ in $17(6 \mathbf{m}) ; 14.5 \%$ in $16(7 \mathbf{m})$ and $17(5 \mathbf{m})$; $9.7 \%$ in $17(7 \mathbf{m})$ and $18(4 \mathbf{m}) ; 8.1 \%$ in $16(8 \mathbf{m}) ; 4.8 \%$ in $18(6 \mathbf{m}) ; 3.2 \%$ in $18(5 \mathbf{m})$.

(6) $\boldsymbol{T K R}-6 \quad$ Seven cytotypes co-occurred: $26.8 \%$ in 16 (6m); $19.5 \%$ in $17(5 \mathbf{m}) ; 17.1 \%$ in $16(7 \mathbf{m}) ; 14.6 \%$ in 17 $(6 \mathbf{m}) ; 9.8 \%$ in $17(7 \mathbf{m}) ; 7.3 \%$ in $16(8 \mathbf{m}) ; 4.9 \%$ in 18 $(4 \mathbf{m})$.

Not only the $2 n=20(4 \mathbf{m})$ but also the $18(6 \mathbf{m})$ cytotypes were considered to be the predominant cytotypes for chromosomal rearrangement of the species and designed as 'JM-type (Japanese mainland-type)' and 'SR-type (Southern Ryukyu-type)' (Kono et al. 2011). The 20 (4m) cytotype has been known in every islands previously investigated, which is north of Takarajima Is., i.e. Tanegashima and Yakushima Is. of the Osumi group and Kuchinoshima, Nakanoshima, Suwanosejima, Akusekijima and Kodakarajima Is. of the Tokara group (Kono et al. 2008 and unpublished data). Additionally, except for the Ryukyus, the same cytotype with $2 n=20$ (4m) was also scattered in many places of the Japanese Archipelago: Nagasaki, Kochi, Ehime, Shimane, Tottori and Fukui Prefectures (Tanaka and Hizume 1978; Kono et al. 2008) and the northern Taiwan [as 20 (4m) TN cytotype in Kono et al. 2012]. However the 20 (4m) cytotype distributed only in TKR-2 on Takarajima Is.

Although the $18(6 \mathbf{m})$ cytotype occurred a few in three localities on the island, it dominantly distributed in the Ryukyu group, especially south Ryukyus, i.e. Sakishima group without Yonagunijima Is. (Oginuma et al. 2004a; Kono et al. 2008), and also eastern Taiwan (Kono et al. 2012).

Besides, odd numbered cytotypes [16 (7m), 17 (5m), $17(6 \mathbf{m}), 17(7 \mathbf{m})$ and $18(5 \mathbf{m})]$ were likely to be derived from inter-cytotypic crossing within a population.

Recently, showing a wide-ranging karyotypic polymorphism of L. mauritiana from the Osumi, Tokara (within Takarajima Is.) and Amami groups, 16 cytotypes were recognized in the area (Kono et al. 2008), of which 11 cytotypes were found in the small island, Takarajima. Moreover, all six localities had mixed-growing multiple cytotypes from five to ten within a population. Therefore, it is suggested that the island showed the highest intraspecific karyotypic diversity both within- and amongpopulations in the Ryukyus.

Dynamics of cytotypes Two years later in 2012, the second investigation of cytotypic frequencies was conducted in the same localities on Takarajima Is. The total number of cytotypes decreased in comparison with that of 2010, i.e. four different chromosome numbers and 10 cytotypes 
with the exception of $2 n=20$ (4m) were detected among 229 individuals (Fig. 1d). The appearance frequency of cytotypes in 2012 and its comparison result with that of 2010 were detailed in the sections below:

(1) $\mathbf{T K R}-1$ Five cytotypes co-occurred: $66.6 \%$ in 17 $(5 \mathbf{m}) ; 16.7 \%$ in $16(6 \mathbf{m}) ; 6.7 \%$ in $17(6 \mathbf{m})$ and $18(4 \mathbf{m})$; $3.3 \%$ in $16(7 \mathbf{m})$.

The total number of cytotypes decreased in 2012 from nine to five, namely, four cytotypes of $16(8 \mathbf{m}), 17(7 \mathbf{m})$, $18(5 \mathbf{m})$ and $18(6 \mathbf{m})$, together accounted $50.0 \%$ in 2010 , could not be found and/or grown in the locality. Instead of them, in 2012, the 17 (5m) cytotype substantially increased by $47.8 \%$ (from 18.8 to $66.6 \%$ ); three cytotypes of 16 $(7 \mathbf{m}), 17(6 \mathbf{m})$ and $18(4 \mathbf{m})$ inconsiderably increased by $0.2 \%$ (3.1 to 3.3 ) and by both $3.6 \%$ (3.1 to 6.7 ), respectively; only the $16(6 \mathrm{~m})$ cytotype decreased by $5.2 \%$ (21.9 to 16.7).

(2) TKR-2 Six cytotypes co-occurred: $42.8 \%$ in 18 (4m); $26.2 \%$ in $17(5 \mathbf{m}) ; 16.7 \%$ in $17(6 \mathbf{m}) ; 7.1 \%$ in 16 $(6 \mathbf{m}) ; 4.8 \%$ in $18(5 \mathbf{m}) ; 2.4 \%$ in $18(6 \mathbf{m})$.

The $20(4 \mathbf{m})$ cytotype accounted for approximately half in 2010, however, it was not found in 2012. On behalf of the cytotype, the $18(4 \mathbf{m})$ cytotype greatly $(35.1 \%$, 7.7 to 42.8$)$ and 17 (5m) slightly (10.8 \%, 15.4 to 26.2$)$ increased. Additionally, two cytotypes of $17(6 \mathbf{m})$ and 18 $(6 \mathbf{m})$ were newly recorded, thus, the number of cytotypes showed a slight increase from five to six in the locality. Among them, the $16(6 \mathbf{m})$ and $18(5 \mathbf{m})$ cytotypes reduced by $16.0 \%$ (23.1 to 7.1 ) and by $2.9 \%$ (7.7 to 4.8 ), respectively.

(3) $\boldsymbol{T K R}-3 \quad$ Seven cytotypes co-occurred: $30.0 \%$ in 16 $(6 \mathbf{m})$ and $17(5 \mathbf{m}) ; 15.0 \%$ in $18(4 \mathbf{m}) ; 10.0 \%$ in $17(6 \mathbf{m})$; $5.0 \%$ in $16(7 \mathbf{m}), 18(5 \mathrm{~m})$ and $19(5 \mathbf{m})$.

The total number of cytotypes decreased in 2012 from ten to seven: three cytotypes of $16(8 \mathbf{m}), 17(7 \mathbf{m})$ and 18 $(6 \mathbf{m})$ could not be found and/or grown in the locality. Among seven cytotypes, both $16(6 \mathbf{m})$ and $17(5 \mathbf{m})$ substantially increased by $13.6 \%$ (16.4 to 30.0 ); the 17 $(6 \mathbf{m}), 18(4 \mathbf{m})$ and $19(5 \mathbf{m})$ cytotypes slightly increased by $0.2 \%$ (9.8 to 10.0$) ; 6.8 \%$ (8.2 to 15.0$) ; 3.4 \%$ (1.6 to $5.0)$, respectively; the $16(7 \mathrm{~m})$ cytotype decreased by 14.7 $\%$ (19.7 to 5.0$)$; the 18 (5m) cytotypes showed the same frequency.

(4) TKR-4 Six cytotypes co-occurred: $41.0 \%$ in 17 (5m); $25.6 \%$ in $16(6 \mathbf{m}) ; 15.4 \%$ in $17(6 \mathbf{m}) ; 12.8 \%$ in 18 $(4 \mathbf{m}) ; 2.6 \%$ in $16(8 \mathbf{m})$ and $18(5 \mathbf{m})$.

In the locality, the $18(5 \mathrm{~m})$ cytotype newly recorded in 2012 replaced by the $16(7 \mathbf{m})$ cytotype in 2010 , hence, the total number of cytotypes remained the same. The 16 $(6 \mathbf{m}), 17(5 \mathbf{m})$ and $18(4 \mathbf{m})$ cytotypes showed a slightly increasing by $4.9 \%$ (20.7 to 25.6$) ; 6.5 \%$ (34.5 to 41.0 ); $5.9 \%$ (6.9 to 12.8 ), respectively. The frequencies of the remaining two cytotypes, $16(8 \mathbf{m})$ and $17(6 \mathbf{m})$, decreased by $11.2 \%$ (13.8 to 2.6$)$ and by $5.3 \%$ (20.7 to 15.4$)$

(5) $\mathbf{T K R}-\mathbf{5}$ Eight cytotypes co-occurred: $29.5 \%$ in 16 $(6 \mathbf{m})$ and $17(5 \mathbf{m}) ; 13.6 \%$ in $18(4 \mathbf{m}) ; 9.1 \%$ in $17(6 \mathbf{m})$ and $18(5 \mathbf{m}) ; 4.6 \%$ in $16(8 \mathbf{m}) ; 2.3 \%$ in $16(7 \mathbf{m})$ and 18 $(6 \mathbf{m})$.

The total number of cytotypes inconsiderably decreased from nine to eight because the 17 (7m) cytotype was not collected in 2012. Among eight cytotypes, the frequencies of the half four cycotypes, $16(6 \mathbf{m}), 17(5 \mathbf{m}), 18(4 \mathbf{m})$ and $18(5 \mathbf{m})$ increased by $10.1 \%$ (19.4 to 29.5$) ; 15.0 \%$ (14.5 to 29.5 ); $3.9 \%$ (9.7 to 13.6 ); $5.9 \%$ (3.2 to 9.1 ), respectively. While, the rest of four cytotypes, $16(7 \mathbf{m}), 16(8 \mathbf{m}), 17$ $(6 \mathbf{m})$ and $18(6 \mathbf{m})$ decreased by $12.2 \%$ (14.5 to 2.3$) ; 3.5$ $\%$ (8.1 to 4.6 ); $7.0 \%$ (16.1 to 9.1 ); $2.5 \%$ (4.8 to 2.3 ), respectively.

(6) TKR-6 Nine cytotypes co-occurred: $27.8 \%$ in 17 $(5 \mathbf{m}) ; 20.4 \%$ in $16(6 \mathbf{m}) ; 16.7 \%$ in $18(5 \mathbf{m}) ; 13.0 \%$ in 17 $(6 \mathbf{m}) ; 9.3 \%$ in $18(4 \mathbf{m}) ; 7.4 \%$ in $18(6 \mathbf{m}) ; 1.8 \%$ in 16 $(7 \mathbf{m}), 16(8 \mathbf{m})$ and $17(7 \mathbf{m})$.

In addition to seven cytotypes in 2010 , the $18(5 \mathbf{m})$ and 18 (6m) cytotypes occupied about a quarter in 2012 were newly found, thus, the total number of cytotypes increased. Among seven cytotypes with the exception of $18(5 \mathbf{m})$ and $18(6 \mathbf{m})$, only two cytotypes of $17(5 \mathbf{m})$ and $18(4 \mathbf{m})$ slightly increased by $8.3 \%$ (19.5 to 27.8$)$ and by $4.4 \%$ (4.9 to 9.3 ); the remaining five cytotypes, $16(6 \mathbf{m}), 16$ (7m), $16(8 \mathbf{m}), 17(6 \mathbf{m})$ and $17(7 \mathbf{m})$, decreased by $6.4 \%$ (26.8 to 20.4$) ; 15.3 \%$ (17.1 to 1.8$) ; 5.5 \%$ (7.3 to 1.8$) ; 1.6$ $\%$ (14.6 to 13.0 ); $8.0 \%$ (9.8 to 1.8 ), respectively.

As the results, with the exception of the $20(4 \mathbf{m})$ cytotype, 10 cytotypes found in 2012 agreed with those of 2010. The respective localities showed an intra-populational variation in cytotypes both years, therefore, the appearance frequencies of cytotypes per unit of area on Takarajima Is. were the highest in the Ryukyus.

In TKR-2, a representative cytotype of 20 (4m), which mainly distributed in the northern Ryukyus and the Japanese mainland, has been collected in 2010, not in 2012. It is suggested that plants with the $20(4 \mathbf{m})$ cytotype were no longer grown in the area due to being inadaptable to the habitat of this island and/or we could not find it in 2012. It might be derived from an artificial disturbance because the locality is adjacent area to the main port of this island as a gateway of people and goods.

Even though, cytotypes would be created and diversified every year among- and within-populations studieand vice and versa on Takarajima Is., intra-populational cytotypic variations were still maintained. Interestingly, three cytotypes, $16(6 \mathbf{m}), 17(5 \mathbf{m})$ and $18(4 \mathbf{m})$, coexisted every locality both in 2010 and 2012. They might be involved in a formation of cytotypes on this island.

Further karyomorphological studies are necessary to clarify the cytogeographical structure of Lysimachia 
mauritiana in the Ryukyu Archipelago.

ACKNOWLEDGMENTS This study was supported by the Grant-inAid for Scientific Research (C) Grant Number 24570111 of the Japan Society for the Promotion of Science (JSPS) (Representative: Kazuo Oginuma).

\section{Literature Cited}

Akiyama, S. 1989. Chromosome numbers of the species in Hydrangea chinensis-complex in the Ryukyu Islands. J. Jpn. Bot. 64: 353-360.

Denda, T. and Yokota, M. 2004. Cytogeography of Ixeris nakazonei (Asteraceae, Lactuceae) in the Ryukyu Archipelago of Japan and Taiwan. J. Plant Res. 117: 3-11.

Iwatsuki, K., Yamazaki, T., Boufford, D. E. and Ohba, H. 1993. (Ed). Flora of Japan. Vol. IIIa. 482 pp. Kodansha, Tokyo.

Kono, Y., Hoshi, Y., Setoguchi, H., Yokota, M. and Oginuma, K. 2008. Aneuploidy and karyotypic polymorphism of Lysimachia mauritiana (Primulaceae) distributed in northern and middle parts in the Ryukyu Archipelago belonging to Kagoshima Prefecture, Japan. Chrom. Bot. 3: 89-93.

Kono, Y., Hoshi, Y., Setoguchi, H., Yokota, M. and Oginuma, K. 2010. Aneuploidy and karyotypic polymorphism of Lysimachia mauritiana (Primulaceae) distributed in middle and southern parts in the Ryukyu Archipelago belonging to Okinawa Prefecture, Japan. Cytologia 75: 3-8.

Kono, Y., Hoshi, Y., Setoguchi, H., Yokota, M. and Oginuma, K. 2011. Distribution patterns of rDNAs and telomeres and chromosomal rearrangement between two cytotypes of Lysimachia mauritiana L. (Primulaceae). Caryologia 64: 91-98.

Kono, Y., Chung, K. F., Chen, C. H., Hoshi, Y., Setoguchi, H., Chou, C. H., Oginuma, K. and Peng, C.-I. 2012. Intraspecific karyotypic polymorphism is highly concordant with allozyme variation in Lysimachia mauritiana (Primulaceae: Myrsinoideae) in Taiwan: implications for the colonization history and dispersal patterns of coastal plants. Ann. Bot. 110: 1119-1135.

Kyoda, S. and Setoguchi, H. 2010. Phylogeography of Cycas revoluta Thunb. (Cycadaceae) on the Ryukyu Islands: very low genetic diversity and geographical structure. Plant Syst. Evol. 288: 177-189.
Levan, A., Fredga, K. and Sandberg, A. A. 1964. Nomenclature for centromeric position on chromosomes. Hereditas 52: 201-220.

Mitsui, Y. and Setoguchi, H. 2012. Recent origin and adaptive diversification of Ainsliaea (Asteraceae) in the Ryukyu Islands: molecular phylogenetic inference using nuclear microsatellite markers. Plant Syst. Evol. 298: 985-996.

Nakamura, K., Denda, T., Kokubugata, G., Suwa, R., Yang, T. Y. A., Peng, C.-I and Yokota, M. 2010. Phylogeography of Ophiorrhiza japonica (Rubiaceae) in continental islands, the Ryukyu Archipelago, Japan. J. Biogeogr. 37: 19071918.

Nomura, N., Takaso, T., Peng, C.-I, Kono, Y., Oginuma, K., Mitsui, Y. and Setoguchi, H. 2010. Molecular phylogeny and habitat diversification of the genus Farfugium (Asteraceae) based on nuclear rDNA and plastid DNA. Ann. Bot. 106: 467-482.

Oginuma, K., Hamada, A., Sato, H., Kono, Y., Yokota, M. and Setoguchi, H. 2004a. Aneuploidy and karyotypic variation of Lysimachia mauritiana (Primulaceae) in the Yonagunijima Island, the Ryukyu Archipelago, Japan. Chrom. Sci. 8: 45-54.

Oginuma, K., Sato, H., Kono, Y., Yokota, M., Setoguchi, H. and Kokubugata, G. 2004b. Karyomorphology of Lysimachia mauritiana (Primulaceae) in the Orchid Island, Taiwan. Chrom. Sci. 8: 63-66.

Ohkawa, T., Yokota, M. and Hoshino, T. 2000. Aneuploidal population differentiation in Carex sociata Boott (Cyperaceae) of the Ryukyu Islands, Japan. Bot. J. Linn. Soc. 132: 337-358.

Ota, H. 2000. The current geographic faunal pattern of reptiles and amphibians of the Ryukyu Archipelago and adjacent regions. Tropics 10: 51-62.

Shimabuku, K. 1997. Check List Vascular Flora of the Ryukyu Islands, Revises Edition. 401 pp. Kyusyu University Press, Fukuoka.

Tanaka, A. and Hizume, M. 1978. Karyomorphological studies on species differentiation in some species of Lysimachia. La Kromosomo II-11-12: 301-312.

Yamashiro, T., Kanemoto, T., Denda, T. and Yokota, M. 2000. Chromosome number variation in Elatostema suzukii (Urticaceae), a species endemic to Okinawa Island, the Ryukyus. Acta Phytotax. Geobot. 51: 21-29. 